\title{
Economic Culture of Students' Communication in Market Conditions
}

\author{
Abdukhakim Mamanazarov ${ }^{1 *}$ \\ ${ }^{1}$ Tashkent Branch of M. V. Lomonosov Moscow State University, Tashkent 100060, Uzbekistan
}

\begin{abstract}
The article substantiates the pedagogical need to develop economic culture among students as Uzbekistan is entering the developed market economy; develops classification and functions of economic culture in student's personality; determines parameters of economic culture development among youth; reveals components and criteria of economic culture among students of higher education institutions; presents methods of economic knowledge expansion; determines culture indicators of entry into economic relations; specifies the content, means, forms, methods and technologies of economic culture development among students; facilitates mechanisms of pedagogical correction based on assessment and diagnostics of the economic culture level formed among students; presents statistically derived methodology of organizing experimental work and its efficiency aimed at developing economic culture among students; designs the research and methodological guidance for improving the training process aimed at developing economic culture among students.
\end{abstract}

\section{Introduction}

In the context of globalization, the need to modernize economic education at higher school in terms of personal economic culture development has increased. Enrichment of the economic education content creates conditions for economic culture development and economic knowledge acquisition. Reforms aimed at economic education modernization, its integration with world educational standards, social and economic development are being implemented in such developed countries as the United States, the Russian Federation, China, Germany, France, Japan, South Korea and Singapore. Raising the level of economic culture of society, adapting to economic activity, changing attitudes towards labour, entrepreneurship and business require the introduction of modern pedagogical technologies in the training process.

The results of economic education analysis in the world and our country show that updating of the economic education content in accordance with modern requirements, and pedagogical process enrichment based on the Concept of National Culture are important for developing students' economic culture essential in their preparation for professional activity. In the system of higher education, teaching various topics related to economic issues creates the basis for economic culture formation among participants of the training process. The development of future specialists' economic culture will become the basis for formation of professional competencies in their future activities. As a result, this will have a positive impact on socioeconomic processes in society.

Socioeconomic changes in Uzbekistan, development of market economic relations require formation of high moral economic culture based on the principle of acceptability through the economic knowledge gaining by young people. There is a problem of cultural and spiritual relationship coordination of a younger generation under various effects produced by the developed market economy. The Strategy of Actions for the Further Development of the Republic of Uzbekistan is focused on upbringing fit, mentally and intellectually developed young people, thinking independently, loyal to the motherland, facilitating democratic reforms and increasing their social activity for developing civic society, which, in turn, also shows future specialists' contribution to economic culture development.

The research is aimed at developing technologies for economic culture formation among non-economic students at higher education institutions under conditions of established market relations and improving the mechanisms of their implementation.

\subsection{Review of foreign scientific researches}

Researches into economic culture development among youth related to formation of their economic knowledge, skills and competencies are carried out in leading research centers and institutions of higher education, for example, Lomonosov Moscow State University, St. Petersburg State University, Moscow State Pedagogical University (Russian Federation), University of Chicago (the USA), Belarus State Economic University (Belarus), Polonia University in Czestochowa (Poland), Kiev National Economic University named after V. Getman (Ukraine) and Rezekne Academy of Technologies (Latvia).

Some results are achieved thanks to global research into the economic culture formation among student

* Corresponding author: abduhakim bazarovich@mail.ru 
youth. In particular, methods of economic culture formation among young people are developed (Lomonosov Moscow State University); directions of students' economic knowledge enrichment responding to social requirements are defined (St. Petersburg State University); the role of new pedagogical technologies in teaching economic subjects is investigated (Moscow State Pedagogical University); market relations impact on making relevant economic decisions and their social advantages and disadvantages are studied (University of Chicago); psychological and pedagogical conditions that ensure efficiency of economic culture formation among students are revealed, practical guidance is presented (Belarus State Economic University); scientific approaches to the socioeconomic and political structure of society and its impact on economic culture are developed (Polonia University in Czestochowa); the concept of consumption culture is integrated into the economic theory and social sciences, and a model of developing consumption culture among future consumers (youth) is created (Kiev National Economic University named after V. Getman); the mechanism combining such students' skills as tourism, services, entrepreneurship and business administration with practice is developed (Rezekne Academy of Technologies).

Development of students' economic culture in leading world universities is carried out in the following priority areas: improving pedagogical mechanisms of organizing economic education activities in the higher education system based on innovative approaches; developing economic culture of future specialists based on the requirements of developed market relationship; improving the content of economic education by means of expanding opportunities for university students to adapt to the economic life of society. Research is conducted to develop students' understanding of the human capital nature and to form competencies for expanding the scope of social relations on this basis.

\subsection{Literature review}

The issues of improving the economic education content through expanding adaptability to the economic life of society are studied by economists, educators, psychologists and philosophers, namely by E. J. Dolan [1], A. B. Mamanazarov [2], James D. Gwartney, Richard L. Stroup, Russell S. Sobel, David A. Macpherson [3], Paul L. Heyne, Peter J. Boettke, David L. Prychitko [4], Ulrich Ph., Lehr U. [5], A. H. Maslow [6], R. B. Reich [7], D. R. Shaffer [8], Stuart H. Brody [9], D. Hirsch [10] and F. Cornali, S. Tirocchi [11].

In the works mentioned above, some research is carried out in the field of creating a stable attitude towards human capital, preparing for work in the developed market environment, enriching economic knowledge and thinking of students. However, the topic Development of Economic Culture among Students of Higher Education Institutions (Taking Non-Economic
Students as an Example) as an independent object of research has not been studied yet.

\subsection{Research methods.}

In the course of the research, methods of theoretical and empirical analysis, observation, diagnostics, interviewing, questioning, modeling, pedagogical experiments, mathematical statistics, and generalization of results are used.

\section{Theoretical and methodological principles of students' economic culture formation}

Graduates of higher education institutions must/should have a certain level of economic culture because they enter into economic relations in the course of work in various spheres of public life (Fig. 1).

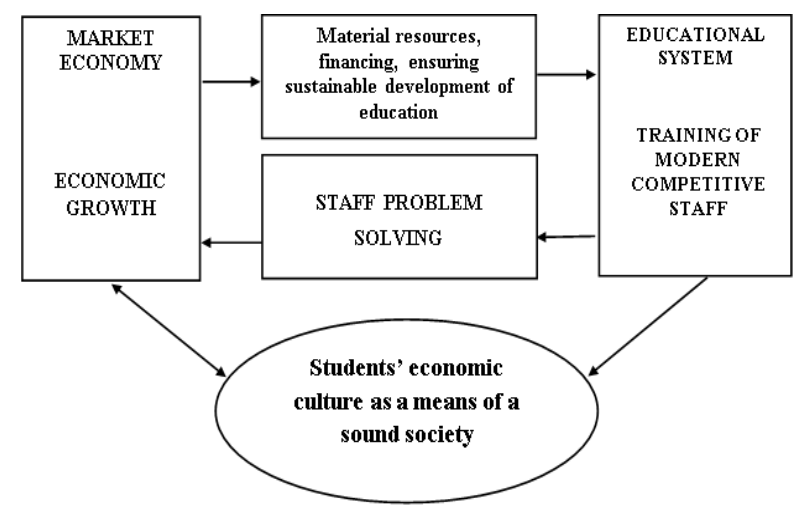

Fig. 1. Interdependence between economy and education during economic culture formation.

The conditions of modern communication substantiate the scientific need for training specialists possessing up-to-date economic, political, legal and professional knowledge which is successfully applied for the benefit of society including: development of curricula for consistent provision of economic knowledge of students in all higher education institutions; providing the educational process with educational materials and didactic projects that combine modern economic knowledge; providing the teaching staff of higher education institutions with the latest economic knowledge during their continuing professional development.

In modern scientific literature, economic culture of communication is studied from a philosophical, social, economic, psychological and cultural point of view. In fact, it reflects the economic behaviour of subjects, which is determined by the laws and principles of the economic system.

Economic culture is a subjective expression of objective reality based on creation of a certain type of economic behaviour that leads to practical goals and actions in the economic sphere being a pursuit of personal interests. 
Due to the fact that development of students' economic culture is a complex and multifaceted process, it is impossible to successfully complete this task during academic hours allocated for the course Economic Theory. For non-economic education, it is possible to organize an optional course called Basics of Personal Consumption and Savings. Its programme, forms and methods of teaching should be based on the requirements of modern economic culture.

In order to improve the process of economic culture development, it is required: firstly, to present economic culture specifying its interdisciplinary relations and emphasizing its economic content; secondly, to enrich Economic Theory course with materials that characterize economic culture; thirdly, to introduce an elective course called Basics of Personal Consumption and Savings in the training process; fourthly, it is recommended to introduce modern pedagogical technologies and interactive methods in all universities contributing to development of economic culture among students.

Today, the following standards and principles of economic culture are important: freedom of property, freedom of entrepreneurship, active high-quality labour, the use of safe technologies, labour efficiency, humanism of economic activity, innovation, moral and legal basics of economic activity, forecasting, etc. They reflect important features and processes of cultural expression in the relationship of business entities.

In this regard, the leading indicators of society's economic culture are: the worldview and professional competence of the subjects involved in the economy; key elements of the economy, qualitative and quantitative classification of growth rates; optimality and stability of the state economic infrastructure; diversified, developed and reliable financial system in accordance with subjects of society; variety of forms of ownership and associated economic mobility; variety of government forms that satisfy mutual interests of a person, society and a state; criteria for moral and legal regulation of the economic relationship system; compatibility of operating culture, material goods and citizens' consumption culture; research and development, humane and ecofriendly economic activity of society.

The components of a person's economic culture include:

1) knowledge (a set of economic ideas about production, exchange, distribution and consumption of material goods) and practical skills;

2) economic thinking (allows for understanding the essence of economic events and processes, putting into practice mastered economic concepts, analyzing specific economic conditions);

3) economic orientation (needs, interests, and motives arising from human activity in the economic field);

4) methods of administration;

5) rules regulating human relations and behaviour (thriftiness, discipline, wastefulness, irresponsibility, extortion, fraud, etc.).

The need to develop students' economic culture is explained by the following:
- social and individual development of students, i.e. moral skills required for solving many problems in daily living, formation of spiritual and economic qualities, development of personal resources, motives, as well as self-knowledge, the ability to adequately assess the readiness for various socioeconomic activities;

- formation of a future specialist's economic attitude, i.e. economic issues of macro- and microeconomic realia understanding, upbringing of an owner - a leader capable of making correct and informed decisions when planning a family household;

- promoting awareness of civic duties and responsibilities, in particular, those of a citizen of a democratic state able to analyze cause-and-effect relationship of economic processes and form the ability of impacting social problem solving with personal views.

In our opinion, goals of economic education at higher education institutions include formation of economic thinking basics among students allowing them to avoid emotional, inconsistent ideas about the issues of the state economic policy; creation of favourable conditions for students' entry into relationship of the developed market economy in order to understand the changes taking place and expected in society; training of an economically literate citizen who is able to analyze economic processes and take an active part in economic activities of the republic; formation of an economic point of view that justifies their actions; acquisition of the ability to make economic decisions independently (as a citizen, an employee, a consumer) in practice, development of the ability to master and apply economic knowledge to analyze and explain economic events and situations.

\subsection{Pedagogical tools for developing students' economic culture}

Development of criteria and their indicators creates certain difficulties due to the fact that the process of forming economic prospects for students is complex and multifaceted. The existing criteria include acquisition of theoretical knowledge; possession of the economic worldview; development of economic thinking; readiness for effective economic activity.

Criteria for formation of economic attitudes among students are availability of economic knowledge; understanding of the essence of economic processes; interaction with subjects of the economic environment and influence; free orientation to the current economic environment.

The study results in identifying the following criteria for determining students' economic culture include availability of cognitive information; the system of values; involvement in intellectual and creative activities; practical work.

Economic knowledge acquired by students should cover two stages of activity. Nevertheless, it is required to selectively include knowledge necessary for students' professional and daily life activities in the curriculum. In most higher education institutions, basic economic knowledge is gained at the Economic Theory course. The level of economic knowledge development among 
students shows that essential economic skills are formed via case study seminars, heuristic and synergistic exercises, and moderation methods. These are determination of cause-and-effect relationship in economic processes; trend analysis of economic reality development in society; critical thinking; highlighting prioritized economic problems; the ability to analyze economic events.

The conducted practical and theoretical analysis suggests specific techniques, methods and technologies for developing economic culture among students. Using these methods, techniques and technologies we tried to develop a certain level of skills and competencies of our students:

Level 1 encompasses students able to reason about certain economic issues, make decisions, and present them adequately. These students can take an inclusive approach to problem solving.

Level 2 identifies students knowing how to reason and make decisions. Students will be able to solve a problem that requires an analysis of the suggested economic situation and make a decision by choosing specific options. Doing that they use different assumptions; summarize information from different sources; draw conclusions based on two or more sources of information.

Level 3 (Support) identifies students who can solve economic problems. Such students work with clearly defined information and cannot use other sources.

A level below level 3 identifies students who lack sufficient problem-solving skills. These students do not fully understand the problem and do not put enough effort into solving it.

The following methods can be used for development of economic culture among students:

1. A problem situation simulated to activate personal knowledge needed for its solution and facilitate students' thinking by setting corresponding educational tasks. The main function of the problem situation is to ensure educational material mastering when difficulties arise. The problem situation includes questions, figures, and graphs related to a phenomenon under study and ways to solve it in the form of incompletely stated ideas.

2. Generalization, coding, optimization of knowledge by using conventional signs, symbols, diagrams, graphs, tables as the main method of teaching and their subsequent deepening in student's mind, complete rethinking, thus providing interaction between a teacher and a student.

3. Independent search for knowledge as a teaching method that allows students to take into account existing knowledge and individual characteristics, set tasks that stimulate creative research, give advice on economic activity, and evaluate the results of the educational process.

\subsection{Model of the pedagogical process aimed at developing students' economic culture}

Modern methods of teaching economics are aimed at achieving the following goals: rapid economic knowledge acquisition; effective organization of economic processes; group economic knowledge acquisition by students; students' adaptation to the microcosm in the developed market economy; provision of insight into the economy of the republic, its current state.

The main features of interactive methods used for development of students' economic culture are:

1) free discussion;

2) free presentation of material;

3) the small number of lectures, the large number of seminars;

4) students' initiative;

5) group assignments;

6) continuous monitoring during a semester;

7) written assignments.

The above-mentioned methods, techniques and technologies promote formation of economic knowledge to a certain extent, which is the basis for students' economic culture.

In the course of experiments aimed at developing students' economic culture, the following shortcomings are identified: inconsistent systematization of modern economic knowledge in the programme/syllabuses, textbooks and study guides; insufficient implementation of pedagogical activities while involving students in economic relations; poor knowledge about operating economic concepts, categories, laws; a lack of creative approaches to solving economic problems and situations; difficulties in analyzing and applying new economic information; a low level of formation of emotional and value-based attitudes in the economy; a lack of selfconfidence in making individual and collective decisions; insufficient formation of skills for assessing economic reality while applying knowledge to practice.

We rely on the following principles of pedagogical activity improvement aimed at economic culture development among students: consideration of specifics and dynamics of the developed market economy; the inclusive approach to providing students with economic knowledge; gradual improvement of curriculum requirements taking into account constant development of economic knowledge; strengthening practical aspects of economic culture development among students; the integrated innovative approach to organizing the process of developing students' economic culture.

Observations have shown that if economic activities are set, imitated and analyzed together with students, they can be effective for development of economic culture. For this purpose, economic education uses various trainings, business games, disputes, discussions, presentations, cases, work in small groups, etc. Individual work with students helps to form economic culture during the educational process through carrying out other types of extracurricular activities.

While working on components of cognitive and informational and practical activities, the implementation of corrective measures aimed at their economic culture development, the following aspects should be considered:

I. Academic work: including tasks aimed at developing economic, logical and analytical thinking of 
a problematic nature, which requires determining not only economic, but also social efficiency of decisions made in the content of academic disciplines.

II. Educational process: analyzing less complex cases aimed at developing the creative potential of students; introducing training activities that allow working on the project called Effective Use of Uzbekistan's Resource Potential within the framework of the course Economic Theory.

III. Extracurricular activities: expanding students' understanding of professions in economic and management fields; demonstrating remarkable examples of life achievements; highlighting valuable, important issues; conducting small researches within the student scientific community (preparing reports for conferences on economics, writing essays on interdependent economic and legal, economic and environmental, economic and political problems) and their involvement into activities organized by group tutors.

Extracurricular activities suggest the tasks that require study of additional literature, as well as research tasks the solutions to which have not been published.

Teaching students of higher education institutions includes various forms and methods, with more attention being paid to extracurricular and independent learning. Dissemination of technical teaching aids, new information technologies, and various free data sources can significantly expand the scope of the traditional academic process.

Using traditional forms of academic activity, students can acquire new knowledge, but their cognitive abilities need stimulating.

In addition to traditional and non-traditional forms of education, out-of-class (extracurricular) activities are especially important for economic culture formation, which is proven by practice and our surveys. Expanding the content of economic courses would allow organizing clubs, scientific circles, and round tables taking into account students' interests and enriching the content of classroom studies.

In the above classes, special attention was paid to determining the requirements for the level of students' training, namely:

- a wider range of knowledge allowing students to demonstrate their abilities at large. The tasks can be either written or oral, individual or group, test, formal, journalistic, requiring preliminary preparation or those that can be completed in class;

- a variety of assignments requiring a wide range of topics covered by the economics course. This enables assessing the level of economic thinking, its completeness and depth, proper use of economic terms, the ability to use knowledge gained elsewhere;

- complexity of tasks corresponding to the level of students' training. They should not be too difficult, but simplified tasks cannot be allowed either, as this negatively affects students' interests in the subject and their cognitive activity;

- excitement of interest provided by tasks with heuristic elements requiring creative approaches to their solution. These tasks should be prepared beforehand. Students' involvement can be encouraged by topicality of the tasks associated with certain current events both in the country and abroad.

\subsection{Efficiency of economic culture development among students of higher education institutions}

The process of students' economic culture formation was organized on the basis of the following experimental plan: determination and analysis of the initial level of students' economic culture in the experimental and control groups; determination of the experimental content; examination of forms, methods and technologies of economic culture formation; determination of the pedagogical conditions of the studied process; generalization and presentation of experimental results accompanied by analysis of positive and negative aspects; development of the economic culture formation model; making adjustments to achieve the desired result and eliminate deficiencies; introduction of programmes aimed at forming economic culture in experimental groups; comparison of the results obtained in the experimental and control groups with the predicted results; creation of the final version of the model of economic culture formation.

In order to develop economic culture among students, we organized elective courses and extracurricular courses during the experimental process.

We relied on students' choice when organizing elective courses aimed at developing economic culture. This course programme is aimed at developing students' skills to make decisions in compliance with the business protocol.

The experiment involved students of Andijan State University, Bukhara State University and the affiliated branch of Lomonosov Moscow State University in the city of Tashkent. A total of 407 students took part in the experiment: 220 of them studied economics following the current programme, and 187 students studied economics on the basis of the modernized programme in terms of the economic culture development.

The results of the formative experiment are a set of tested pedagogical forms, methods and technologies selected in accordance with the stages of economic culture development and the results of corrective work. This allows managing economic culture development in accordance with theoretical, psychological and pedagogical mechanisms, and confirms efficiency of economic education.

As a result of the experiment, the economic culture development system was formed (Fig. 2).

The research results allow for concluding that the level of economic culture development and its correspondence to the existing economic relations in society has increased in the experimental groups. The developed programme of economic education and teaching methods ensure high-quality acquisition of knowledge, their application in practice significantly impacts development of economic culture among students (Table 1). 


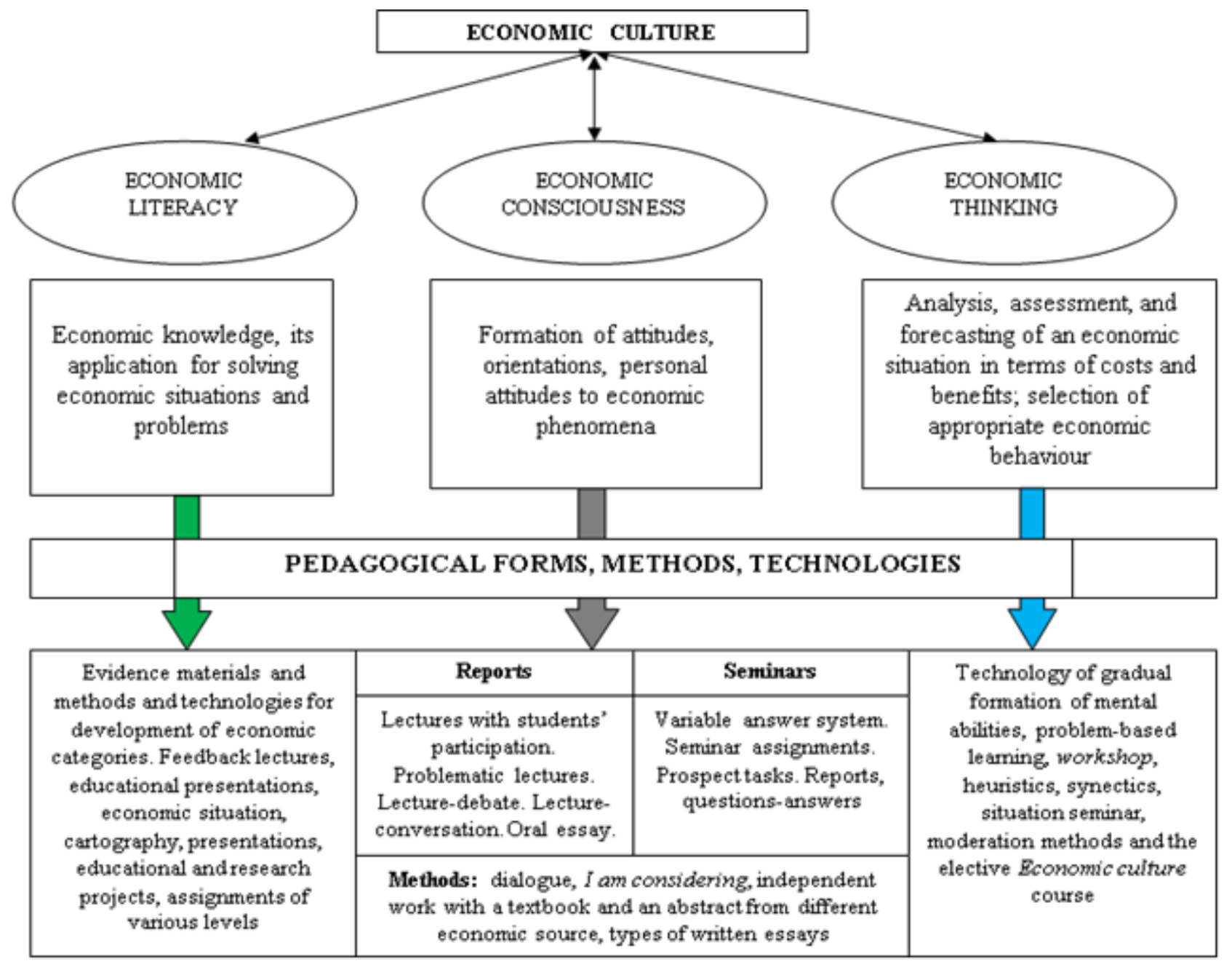

Fig. 2. Classification and functions of students' economic culture development.

Table 1. The efficiency level of the economic culture development among students at the beginning and at the end of the experiment.

\begin{tabular}{|c|c|c|c|c|c|c|}
\hline \multirow{2}{*}{ Terms } & \multirow{2}{*}{ Groups } & \multirow{2}{*}{$\begin{array}{l}\text { Number of } \\
\text { students }\end{array}$} & \multicolumn{4}{|c|}{$\begin{array}{c}\text { Formation levels } \\
\text { in numbers and percentage }\end{array}$} \\
\hline & & & High & Above average & Average & Low \\
\hline \multirow{4}{*}{$\begin{array}{l}\text { At the beginning of } \\
\text { the experiment }\end{array}$} & \multirow{2}{*}{ Experimental group } & \multirow[t]{2}{*}{216} & 19 & 41 & 95 & 61 \\
\hline & & & $8.9 \%$ & $18.9 \%$ & $44.1 \%$ & $28.1 \%$ \\
\hline & \multirow[t]{2}{*}{ Control group } & \multirow[t]{2}{*}{191} & 24 & 48 & 73 & 46 \\
\hline & & & $12.3 \%$ & $25 \%$ & $38.4 \%$ & $24.3 \%$ \\
\hline \multirow{4}{*}{$\begin{array}{l}\text { At the end of the } \\
\text { experiment }\end{array}$} & \multirow[t]{2}{*}{ Experimental group } & \multirow[t]{2}{*}{216} & 71 & 84 & 43 & 18 \\
\hline & & & $32.8 \%$ & $38.8 \%$ & $19.9 \%$ & $8.3 \%$ \\
\hline & \multirow[t]{2}{*}{ Control group } & \multirow[t]{2}{*}{191} & 25 & 70 & 50 & 46 \\
\hline & & & $13.1 \%$ & $36.6 \%$ & $26.2 \%$ & $24 \%$ \\
\hline
\end{tabular}

The results of Table 1 allow determining the average level of knowledge acquisition that reveals the level of efficiency of economic culture development by applying the Student and Pearson mathematical and statistical method $\chi 2$. The brief essence of the issue is as follows: there are two general data sets.

One of them is the average score of the students in the experimental group, and the other is the average score of the students in the control group. The grades are considered to have normal distribution. This assumption is valid, since the conditions for approximation to the normal distribution are simple and they are satisfied.

Based on the above tables, the hypothesis $\mathrm{H} 1$ is selected, it shows efficiency of teaching students in the experimental and control groups and the hypothesis $\mathrm{H} 0$ contradicts it.

In accordance with the indicators of the above table, the diagrams corresponding to these samples are as follows (Fig. 3, 4). 


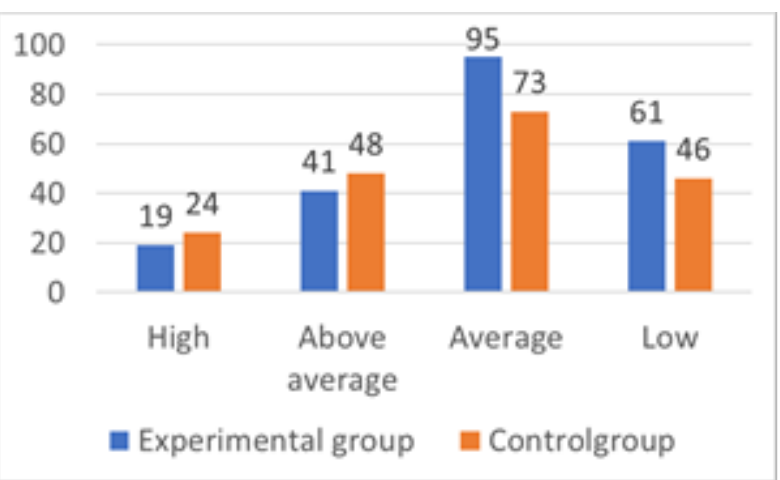

Fig. 3. At the beginning of the experiment, $\%$.

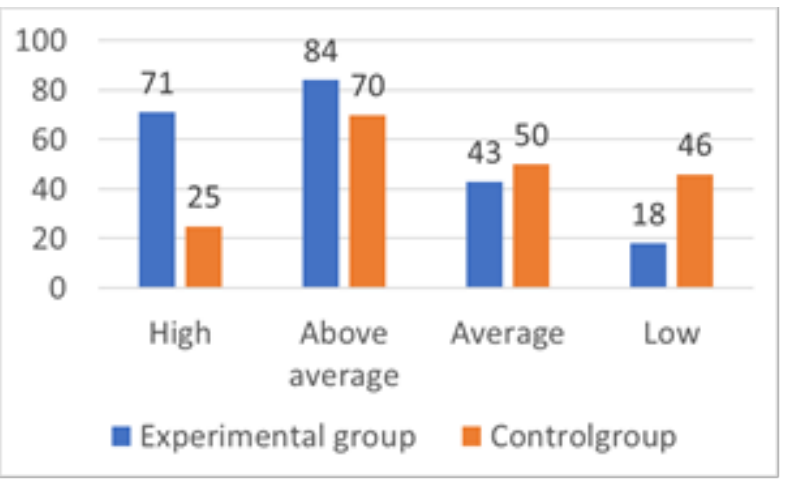

Fig. 4. At the end of the experiment, $\%$.

Based on the results obtained, mathematical statistical analysis was performed to determine the standard deviation, sample variance, variance indices, the Student's selection criterion, degrees of freedom based on the Student's criterion, the Pearson's acceptability criterion, and reliable deviations from the results for the case at the end of the experiment. They are shown in Table 2:

Table 2. The parameters of the economic model and mathematical statistical analysis of the experiment results.

\begin{tabular}{|c|c|c|}
\hline $\bar{X}$ & 2.09 & 2.97 \\
\hline $\bar{Y}$ & 2.25 & 2.39 \\
\hline$S_{x}^{2}$ & \multirow{9}{*}{$\begin{array}{l}\text { Efficiency } \\
\text { is not achieved } \\
\text { at the beginning } \\
\text { of the experiment }\end{array}$} & 0.2491 \\
\hline$S_{y}^{2}$ & & 0.9779 \\
\hline$C_{x}$ & & 1 \\
\hline$C_{y}$ & & 3 \\
\hline$T_{x, y}$ & & 7.34 \\
\hline$K$ & & 285.7 \\
\hline$X_{n, m}^{2}$ & & 36.09 \\
\hline$\Delta_{x}$ & & 0.07 \\
\hline$\Delta_{y}$ & & 0.14 \\
\hline
\end{tabular}

From the results obtained, it is known that average efficiency in the experimental group has increased by $14.5 \%$ compared to the control group.

On the basis of the above results, when calculating the qualitative indicators of the experimental work, the following is achieved.

It is known that $\overline{\mathrm{X}}=2,97 ; \bar{Y}=2,39 ; \Delta_{x}=0,07 ;$ $\Delta_{y}=0,14$.

Here quality indicators are:

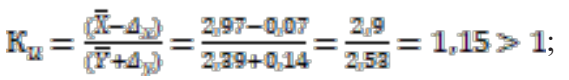

$$
\begin{aligned}
& \mathbb{K}_{b}=\left(\overline{\mathrm{X}}-\Delta_{x}\right)-\left(\bar{Y}-\Delta_{y}\right) \\
& K_{b}=(2,97-0,07)-(2,39-0,14)=0,65 \text {; } \\
& \mathbb{K}_{b}>0 \text {. }
\end{aligned}
$$

The obtained results show that the criterion for assessing the training efficiency suddenly increases, and the criterion for assessing the level of knowledge exceeds zero. It is known that the efficiency in the experimental group grew higher than that in the control group.

It should be noted that economic culture is higher among those who studied Economics after updating the programme regarding economic culture development than among those who studied Economics following the standard programme.

When solving financial problems, students' economic knowledge is formed, while their socially significant relations are moderately polished.

\section{Conclusion}

As a result of the research, the following conclusions are drawn:

1. In developed market conditions of Uzbekistan, economic culture development of a person with a strong position is of particular importance. This requires regular acquisition of economic knowledge; development of students' economic knowledge, consciousness and thinking; formation of competencies for interpersonal economic relations. To achieve this goal, it is necessary to provide not only students of economic faculties, but also future non-economic specialists with new economic knowledge in order to give them a clear idea of socioeconomic development.

2. To carry out such pedagogical activity, first of all, it is necessary to enrich the content of economic education and develop mechanisms for organizing this process considering international experience. Students are taught that economic culture is a subjective expression of objective reality based on the creation of a certain type of economic behaviour that leads to practical goals and actions in the economic sphere being a pursuit of personal interests.

3. Economic culture development is an integral part of national culture. Economic culture performs certain functions in the community, such as translation, 
selection, innovation, regulation, worldview, humanism, axiology, adaptation, stabilization.

4. In order to train a competitive specialist possessing up-to-date economic, political, legal and professional knowledge and apply it successfully satisfying the community's needs, the following problems are to be solved: development of curricula for consistent provision of economic knowledge at all higher education institutions; provision of the educational process with training materials and didactic projects that comprise modern economic knowledge; provision of the university staff with the latest economic knowledge in the process of their continuing professional development.

5. The psychological and pedagogical approach to development of students' economic culture made it possible to single out a number of components in its structure. The description of economic culture components along with psychological and pedagogical features of economic culture development created the basis for solving the problem of identifying the assessment criteria of the students' economic culture level. The research has defined the following criteria: availability of cognitive information; the system of values; intellectual and creative activity; practical activities.

6. Along with solving the economic problems assigned to the students, they have the opportunity to acquire knowledge that forms the basis of economic culture: the process of acquiring new knowledge is the main point for economic culture development; problem assignments ensure successful mastering of economic culture elements; problem solving tasks also allow students to control the level of their economic culture.

7. Teaching economic concepts and patterns prepares university graduates for social life, in which they form psychological stability in relation to possible difficulties associated with unemployment, competition, their work and profession, change of residence.

8. The conducted practical and theoretical analysis has become the basis for specifying methods, techniques and technologies to develop students' economic culture.

9. Correction of pedagogical activity aimed at developing students' economic culture was based on certain principles: taking into account specifics of the developed market economy and development dynamics; the inclusive approach to the presentation of the economic content; gradual improvement of the requirements for the curriculum in terms of continuous development of economics; facilitating practical aspects of economic culture development among students; the integrated innovative approach to organizing the process of economic culture development.

10. The results of the experiment have shown that use of innovative methods in the pedagogical process aimed at developing economic culture among students helps to elaborate their economic thinking, interpretation of current economic reforms, and navigate in modern economic life making optimal decisions in any economic situation.

11. It is possible to expand the sphere of students' economic culture by choosing the content of extracurricular activities of certain complexity. For this purpose, special extracurricular courses are included in the training programme. The content of special courses is inextricably linked with that of classroom studies.

12. The experiment has been carried out relying on methodological approaches to its organization. Theoretical and empirical data indicate that quality and efficiency of economic education and training of specialists for future social and practical activities depend on the development level of economic thinking and consciousness that characterize students' economic culture.

The results of the experimental work have confirmed the correctness of the idea expressed in the research.

Based on the above conclusions, we provide the following recommendations:

- introduction of the elective course Theory and Practice of Economics at non-economic departments of all higher education institutions on the territory of the republic;

- introduction of regular seminars at higher education institutions on the topic The Role of Individual Culture in Development of the Economic Life of Society taking into account sustainable development of the economic life of society;

- introduction of the latest economic concepts into the content of academic disciplines at higher education institutions on the basis of the integrative approach;

- organization of trainings, round tables, press conferences on economic issues for the teaching staff and students of higher education institutions.

\section{References}

1. Edwin G. Dolan, The Austrian Paradigm in Environmental Economics: Theory and Practice, Quarterly Journal of Austrian Economics, 17 (2) (2014)

2. A. B. Mamanazarov (ed.),, An interdisciplinary approach to the process of forming an economic culture (Fan va texnologiya, Tashkent, 2017).

3. James D. Gwartney, Richard L. Stroup, Russell S. Sobel, David A. Macpherson, Microeconomics: Private and Public Choice (Cengage Learning, 2014)

4. Paul L. Heyne, Peter J. Boettke, David L. Prychitko, The Economic Way of Thinking: Pearson New International Edition (Pearson Education, 2013)

5. Ulrich Ph., Lehr U., Economic effects of an Emobility scenario - input structure and energy consumption, Economic Systems Research, 32:1, 84-7, (2020) doi: 10.1080/09535314.2019.1619522

6. Maslow A. H. A theory of human motivation. Psychological Review, 50(4), 370396. (1943). doi:10.1037/h0054346

7. Reich R. B. (ed.), The System: Who Rigged It, How We Fix It (Pan Macmillan UK, 2020) 
8. Shaffer David R., Social and Personality Development (United States, Cengage Learning, 2008)

9. Brody Stuart H., The Law of Small Things: Creating a Habit of Integrity in a Culture of Mistrust (BerrettKoehler Publishers, 2019)

10. Hirsch D., Cultural context in marketing communication on international market, Marketing of Scientific and Research Organisations, 12, (2014) doi: 10.14611/minib.12.02.2014.08

11. Cornali F., Tirocchi S. Globalization, Education, Information and Communication Technologies: What Relationships and Reciprocal Influences?, Procedia - Social and Behavioral Sciences, 47 (2012) doi: 10.1016/j.sbspro.2012.06.949 